\title{
Energy efficiency in smart home system
}

\author{
Ratko Ivanov*, Vlatko Ivanov**, Cveta Martinovska Bande ${ }^{* * *}$ \\ * Faculty of Computer Science, University Goce Delcev - Stip, Republic of North Macedonia \\ ${ }^{* *}$ Faculty of Computer Science, University Goce Delcev - Stip, Republic of North Macedonia \\ *** Faculty of Computer Science, University Goce Delcev - Stip, Republic of North Macedonia
}

DOI: $10.29322 / I J S R P .10 .09 .2020 . p 10581$

http://dx.doi.org/10.29322/IJSRP.10.09.2020.p10581

\begin{abstract}
With the advancement of technology, we are constantly striving to automate processes that would make everyday life easier and at the same time reduce daily costs. So today there are smart homes that aim to reduce daily obligations and costs, and at the same time increase the safety and comfort of home. Smart Home technology is a general term that refers to homes that have comforts related to communication technologies, enabling automatic or remote controls. Smart Home offers opportunities to save energy and reduce costs, improve the quality of life and increase security. Home and building automation provide comfort, security, energy savings, flexibility and adaptability to future development. The purpose of this paper is to make a prototype of a smart home. It will be equipped with several sensors and a NodeMcu.
\end{abstract}

Index Terms- Energy Efficiency, IoT, NodeMcu, Smart Home

\section{INTRODUCTION}

$\mathrm{T}_{1}^{\mathrm{s}}$

he idea of a smart home has been growing steadily in recent years. In 1992, Lutolf provided the first definition for a smart home [1]. According to Lutolf, "the smart home concept is the integration of different services within a home by using a common communication system. It assures an economic, secure, and comfortable operation of the home and includes a high degree of intelligent functionality and flexibility."

Building automation solutions and management are a real challenge for engineers. Improving the overall energy efficiency of a building also depends on the implementation of renewable energy sources and energy storage. Implementation of such technology saves 30-40\% energy and reduces emissions. Technological advances in the way energy is utilized and equipment installed require high quality and accuracy.

\section{ENERGY EFFICIENCY}

Energy efficiency is performing the same or a larger amount of activities with the same or a smaller amount of energy consumed (heat, electricity) and with a lower emission of carbon dioxide into the atmosphere.

Inefficient use of electricity increases in proportion to the increase in electricity consumption, increased activity in the economy and the use of outdated technology.

In addition, this increases the adverse environmental impact and consumes resources that cannot be recovered, and the next generations will not have adequate access to them.

Energy efficiency brings great benefits in everyday life:

1) reducing the need for energy imports;

2) more efficient heating and cooling;

3) saving money;

4) better environment;

5) reducing the risk of various diseases caused by harmful substances, which are a result of energy production;

6) increase the number of jobs;

7) increasing the use of renewable energy sources.

Using a smart home for energy efficiency can save costs so far, which means that investments to increase energy efficiency pay off. 


\section{SYSTEM ARCHITECTURE}

The implemented system consists of a NodeMcu which is used as a main processing unit for the entire system and all the sensor and devices can be connected with the microcontroller. The sensors can be operated by the user through website which collects the data from sensors through mqtt protocol. The system architecture is shown in Fig. 1.0 below.

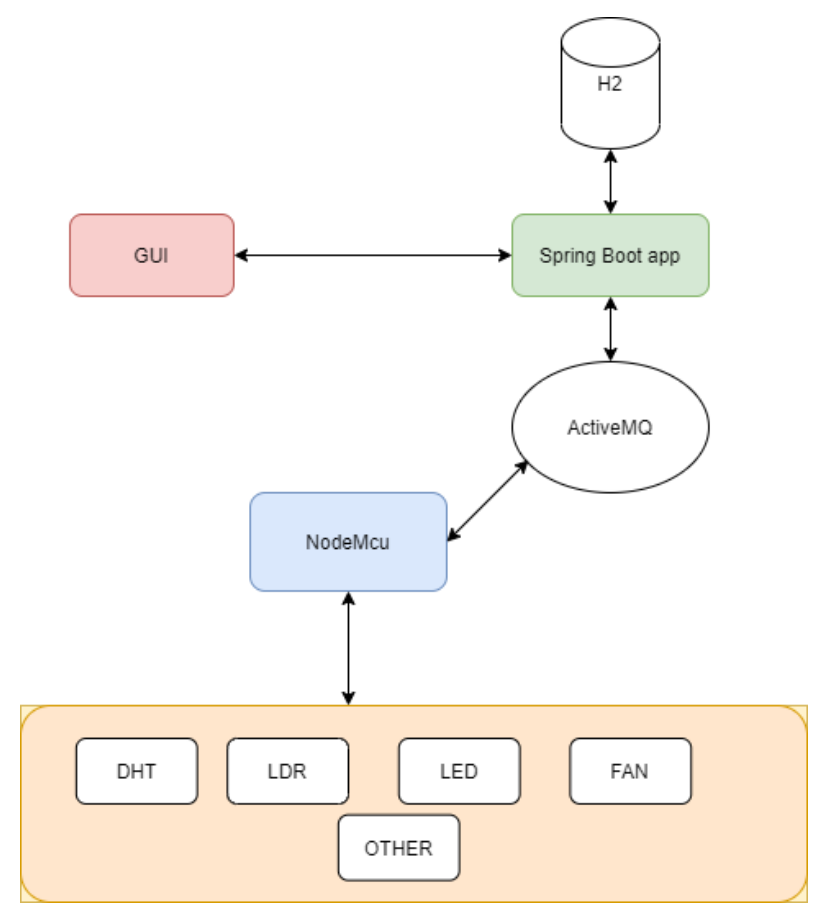

Figure 1.0 System Architecture

Sensors and devices are connected to NodeMcu which communicates with Spring Boot application through ActiveMq broker via mqtt protocol. From the GUI we can control the devices and monitor their measures.

\section{NODEMCU}

NodeMcu is an open source IoT platform. It includes firmware which runs on the ESP8266 Wi-Fi SoC from Espressif Systems, and hardware which is based on the ESP12 module. It will be used as main processing unit for the entire system and sensors. An image of NodeMcu is shown in Fig. 2.0 below.

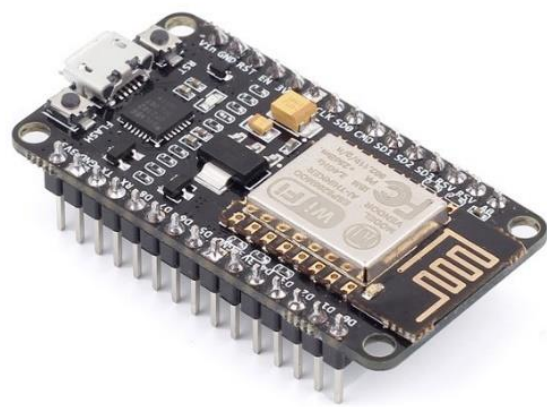

Figure 2.0 NodeMcu 


\section{Sensors:}

1) The humidity and temperature of the room are measured by DHT11 sensor. The DHT11 is a digital temperature and humidity sensor. It uses a capacitive humidity sensor and a thermistor to measure the surrounding air, and spits out a digital signal on the data pin. An image of DHT11 is shown in Fig. 3.0 below.

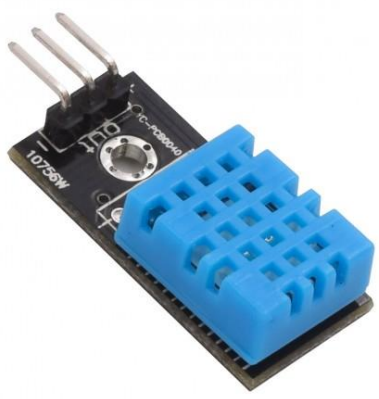

Figure 3.0 DHT

2) Light dependent resistor is a component that is sensitive to light. When light falls upon it then the resistance changes. It will be used to measure the outdoor light. When there is enough brightness that can light up the yard, the system will automatically turn off the lights. An image of LDR is shown in Fig 4.0 below.

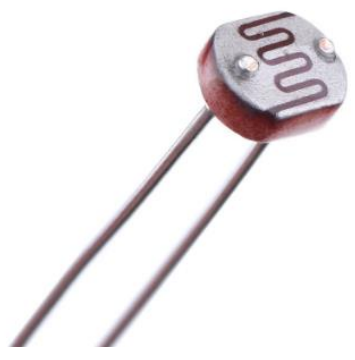

Figure 4.0 LDR

3) A light-emitting diode (LED) is a semiconductor light source that emits light when current flows through it. It will be used to represent the light. When the system receives measurements that there is enough light then the led will be automatically turned off. An image of LED is shown in Fig. 5.0 below. 


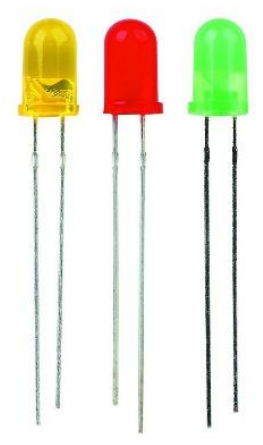

Figure 5.0 LED

4) The maintenance of the temperature in the home will be through an $3 \mathrm{~V}$ DC motor and fan. An image of FAN is shown in Fig. 6.0 below.

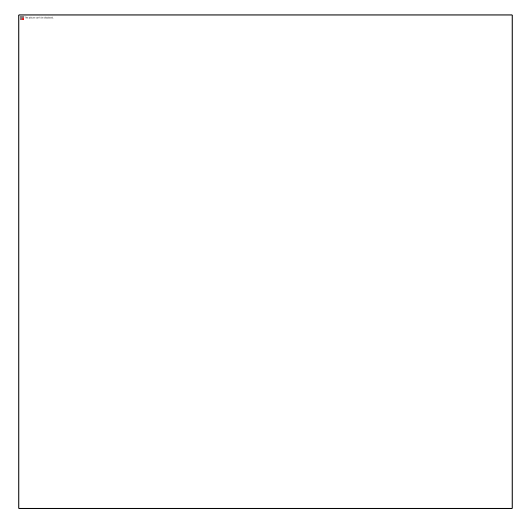

Figure 6.0 FAN

5) The reed switch is an electrical switch operated by an applied magnetic field. An example of a reed switch application is to detect the opening of a door, windows, when used as a proximity switch for a security alarm. An image of Reed Switch is shown in Fig 7.0 below.

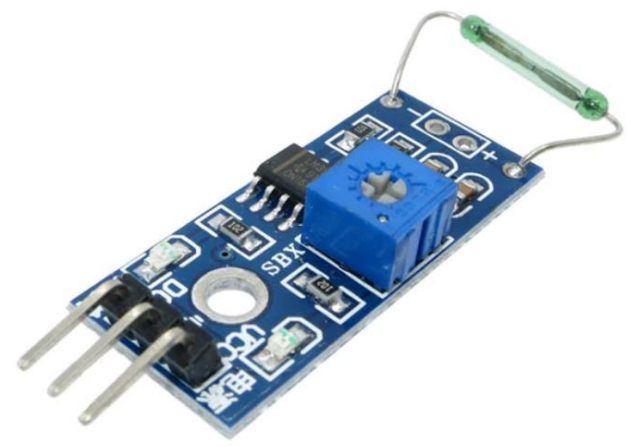

Figure 7.0 Reed Switch 


\section{GUI}

This web application is made with Angular and communicate with Spring Boot application through Rest API and WebSocket's. Through this GUI we can control our home and devices. For example, if we turn on the light, then the system sends request to the spring boot application. This web application also represents an analytical module where several calculations and graphs are presented.

\section{Spring boot application}

This application is for controlling, calculation and analytics for the data from the sensors. In this application we have the state of every sensor and device stored in $\mathrm{h} 2$ database. Calculations and analytics are also saved in $\mathrm{h} 2$ database. The application communicates with the GUI through REST API and WebSocket's, and it communicates with NodeMcu via Mqtt protocol through ActiveMq.

\section{ACTIVEMQ}

ActiveMQ is an open source protocol developed by Apache which functions as an implementation of message-oriented middleware (MOM). Its basic function is to send messages between different applications. In the system it is used as a message broker between all components.

\section{IMPLEMENTATION}

For achieving energy efficiency, we have several use cases:

1)If the FAN is active and some window is opened, then the "smart home" will close the window. Then it will send notification to our system where it will count the energy savings.

2)If there is no motion in the room after some period, the system will turn off the light.

3)When there is enough brightness that can light up the yard, the system will automatically turn off the lights.

4)When there is enough brightness outside that can light up the room, the system will turn off the lights in the room.

5)When it is cheap electricity time then the system will notify the user to turn on the laundry and other stuffs.

On this Figure 8.0 below we can see that we can pick some date range and see the status of our energy efficiency for that period. The price for the $\mathrm{kWh}$ is used from North Macedonia electricity provider which is 4.44 denars.

The result:

1) Total money saved

2) Total money spent

3) Total kWh saved

4) Total kWh spent 


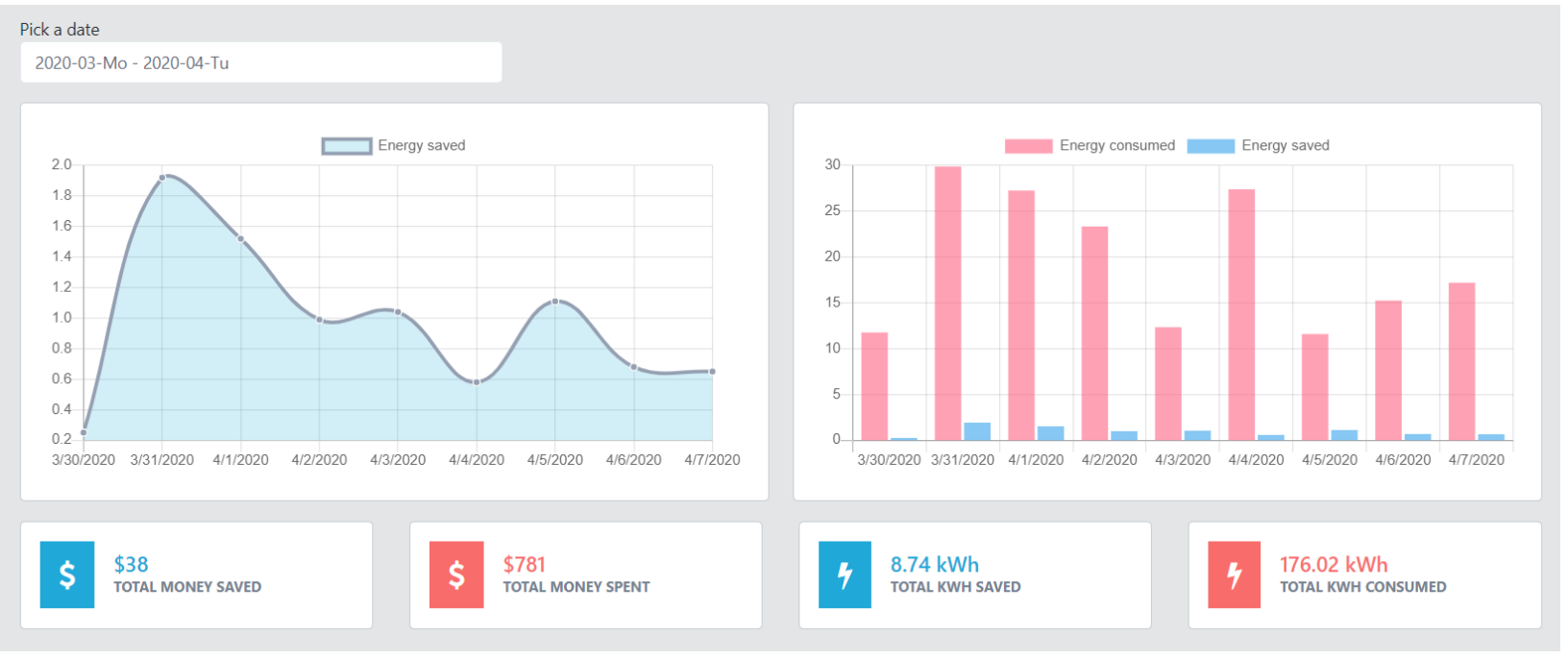

Figure 8.0 Results

\section{CONCLUSION}

Heating and cooling costs are the \#1 expense in most homes. Naturally, it's the first place many homeowners look to cut costs. What they should do is figure out how to use energy more efficiently, while at the same time achieving the comfort, health, and home protection benefit. There are many motivations to improve energy efficiency. The reducing of the energy consumption may result in a financial cost saving to consumers if the energy savings offset any additional costs of implementing an energy-efficient technology. In this paper we have presented a project for smart home energy efficiency. The results obtained were above satisfactory and can be further improved by adding more devices and adding voice commands.

\section{REFERENCES}

[1] Lutolf, R. Smart home concept and the integration of energy meters into a home-based system. In Proceedings of the Seventh International Conference on Metering Apparatus and Tariffs for Electricity Supply 1992, Glasgow, UK, 17-19 November 1992; pp. 277-278.W.-K. Chen, Linear Networks and Systems (Book style). Belmont, CA: Wadsworth, 1993, pp. 123-135.

[2] Amita Kapoor, "Hands-On Artificial Intelligence for IoT: Expert Machine Learning and Deep Learning Techniques for Developing Smarter IoT Systems", (2019, January)

[3] Adam Freeman, "Pro Angular 6", (2018, October)

[4] Adriansyah, A.; Dani, A.W., "Design of Small Smart Home system based on Arduino", Electrical Power, Electronics, Communications, Controls and Informatics Seminar (EECCIS), 2014, Malang, pp.121 - 125, 27-28 Aug. 2014

[5] Catalin Batrinu, "ESP8266 Home Automation Projects: Leverage the Power of this Tiny WiFi Chip to Build Exciting Smart Home Projects “, (2017, November)

[6] Craig Walls, "Spring Boot in Action" (2016)

[7] C.-Y. Chen, Y.-P. Tsoul, S.-C. Liao, C.-T. Lin, "Implementing the design of smart home and achieving energy conservation," in Proc. 7th IEEE Int. Conf. on Industrial Informatics (INDIN), 2009, pp.273 - 276.

\section{AUTHORS}

First Author - Ratko Ivanov, Master's student, Faculty of Computer Science, University Goce Delcev - Stip, Republic of North Macedonia ratko.101405@student.ugd.edu.mk

Second Author- Vlatko Ivanov, Master's student, Faculty of Computer Science, University Goce Delcev - Stip, Republic of North Macedonia vlatk0o@ hotmail.com.

Third Author-Cveta Martinovska Bande, Full Professor, Faculty of Computer Science, University Goce Delcev - Stip, Republic of North Macedonia cveta.martinovska@ugd.edu.mk 